\title{
Genetic analysis of products of conception using a HLPA/SNP-array strategy
}

Jun Mao ${ }^{1,2 \dagger}$, Huiling Wang ${ }^{3 \dagger}$, Haibo $\mathrm{Li}^{4 \dagger}$, Xiaoyan Song ${ }^{1,2}$, Ting Wang ${ }^{1,2}$, Jingjing Xiang ${ }^{1,2^{*}}$ (D) and Hong Li ${ }^{1,2^{*}}$

\begin{abstract}
Background: Fetal chromosomal abnormalities was the most frequent cause of miscarriage, and the traditional testing method G-banded karyotyping has limitations. Then high-throughput ligation-dependent probe amplification (HLPA) and single nucleotide polymorphism array (SNP-array) were introduced for genetic analysis on products of conception (POC).

Methods: HLPA and SNP-array analysis were combined. POC samples were initially tested using HLPA, followed by SNP-array analysis on samples that were found to be normal by HLPA.

Results: Of the 326 POC samples tested, the overall abnormality rate was 54.6\% (178/326), including 44.8\% (146/ 326) chromosomal abnormalities identified by HLPA and 9.8\% (32/326) additional chromosomal abnormalities further detected by SNP-array.
\end{abstract}

Conclusions: The combination of HLPA and SNP-array analysis is an efficient and cost-effective strategy for genetic analysis of POC.

Keywords: HLPA, SNP-array, products of conception, chromosomal abnormality, miscarriage

\section{Background}

Miscarriage is defined as the spontaneous loss of pregnancy before 24 weeks of gestation, and $10-15 \%$ of clinically recognized pregnancies end in miscarriage [1]. Multiple factors are associated with miscarriage, including genetic, structural, infective, endocrine, immune factors and so on [2]. Among these, fetal chromosomal anomalies was the most frequent cause, which accounts for more than $50 \%$ of first-trimester miscarriage [3].

G-banded karyotyping is the conventional cytogenetic technique used in analysis of products of conception (POC), which could detect chromosomal aneuploidies, structural abnormalities, duplications or deletions $(>5$ $10 \mathrm{Mb}$ ), polyploidies and mosaicism. However, it has several limitations such as low resolution, high rates of culture failure and long reporting time [4]. Then some rapid techniques for genetic testing of chromosomal aneuploidies have emerged including quantitative fluorescent PCR (QF-PCR), fluorescence in situ hybridization (FISH),

\footnotetext{
*Correspondence: xiangjingjing2013@163.com; hongliszivf@163.com

†Jun Mao, Huiling Wang and Haibo Li are contributed equally to this work.

${ }^{1}$ Center for Reproduction and Genetics, The Affiliated Suzhou Hospital of

Nanjing Medical University, Suzhou, Jiangsu, China

Full list of author information is available at the end of the article
}

BACs-on-Beads (BOBs) and multiple ligation-dependent probe amplification (MLPA), but these techniques also have drawbacks such as restricted coverage and resolution on the whole genome due to limited number of chromosomal probes [5]. The advent of chromosomal microarray analysis (CMA) and next generation sequencing (NGS) enable us to identify submicroscopic imbalances on the whole genome with higher resolution [6, 7]. CMA includes array-based comparative genomic hybridization (aCGH) and single nucleotide polymorphism array (SNParray), and it is considered to be the fist-tier testing for detection of copy number variations (CNVs) [8].

In 2016, a new approach called high-throughput ligationdependent probe amplification (HLPA) was established for genetic analysis of POC, which has been proved to be a rapid and accurate method for aneuploidy screening of 24 chromosomes in spontaneous abortion specimens $[9,10]$. In this study, a HLPA/SNP-array strategy was applied to detect chromosomal abnormalities in POC, and the results indicated that the HLPA/SNP-array strategy was an efficient and economic method with improved diagnostic yield.

(c) The Author(s). 2019 Open Access This article is distributed under the terms of the Creative Commons Attribution 4.0 International License (http://creativecommons.org/licenses/by/4.0/), which permits unrestricted use, distribution, and reproduction in any medium, provided you give appropriate credit to the original author(s) and the source, provide a link to the Creative Commons license, and indicate if changes were made. The Creative Commons Public Domain Dedication waiver (http://creativecommons.org/publicdomain/zero/1.0/) applies to the data made available in this article, unless otherwise stated. 


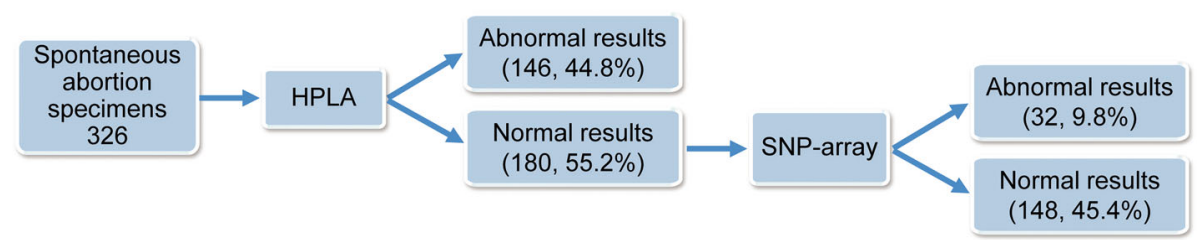

Fig. 1 The analysis strategy of spontaneous abortion specimens

\section{Methods Samples}

This study was approved by the institutional ethics committee of the Affiliated Suzhou Hospital of Nanjing Medical University, and written informed consent were obtained from all participants in the study. A total of three hundred and twenty six specimens of spontaneous abortion including chorionic villi and fetal tissues were collected at the Center for Reproduction and Genetics, the Affiliated Suzhou Hospital of Nanjing Medical University, Suzhou, Jiangsu, China, and the mean gestational age was 9.4 weeks (range: 5.1-17.1 weeks). The received POC samples were rinsed by saline solution immediately, and chorionic villi were separated using needles under a dissecting microscope. Then genomic DNA was extracted by QIAamp DNA Mini Kit (Qiagen GmbH, Hilden, Germany), and maternal cell contamination were ruled out for all the 326 samples by short tandem repeat (STR) profiling using Microreader $^{\mathrm{rm}} 21$ (Direct) ID System (Microread, Suzhou, China), which was used to simultaneously amplify 20 STR loci and the amelogenin gender marker.

\section{HLPA assay}

HLPA assay was conducted using a Human 24 Chromosomes Aneuploidy Detection Kit (N9002, Genesky, Suzhou, China) according to the manufacturer's instructions. Briefly,
200 ng of genomic DNA was added into a ligation premix for ligation reaction, then the ligation products were amplified by PCR reaction. PCR products were diluted and analyzed by capillary electrophoresis using an ABI 3130 Genetic Analyzer (Applied Biosystems, Foster City, CA, USA). Data analysis was performed by GeneMapper 5 (Applied Biosystems, Foster City, CA, USA) and CNV Reader 1.0 (Genesky, Suzhou, China). The CNV value of each target was calculated with a cut-off value 0.8-1.2 for one copy, 1.6-2.3 for two copies, and 2.5-3.5 for three copies. The $\mathrm{CNV}$ values of all probes on a chromosome between 2.5 to 3.5 suggest trisomy, while the CNV values of all probes on a chromosome in the range of 0.8 to 1.2 indicates monosomy. The CNV values of at least three consecutive probes on a chromosome within 2.5-3.5 or 0.8-1.2 may suggest partial duplication or partial deletion on the chromosome, and $\mathrm{CNV}$ values of at least three consecutive probes on a chromosome within 2.32.5 or 1.3-1.5 may indicate mosaicism or contamination.

\section{SNP-array analysis}

The SNP-array analysis was performed on the Affymetrix CytoScan platform (Affymetrix, Santa Clara, CA, USA) following the manufacturer's protocol. In brief, $250 \mathrm{ng}$ of genomic DNA was digested, ligated, PCR amplified, purified, fragmented, labelled and hybridized to the Affymetrix $750 \mathrm{~K}$ array, which includes 550,000 CNV markers and 200,000 SNP markers. After washing, staining and scanning of arrays, raw data were analyzed by Chromosome

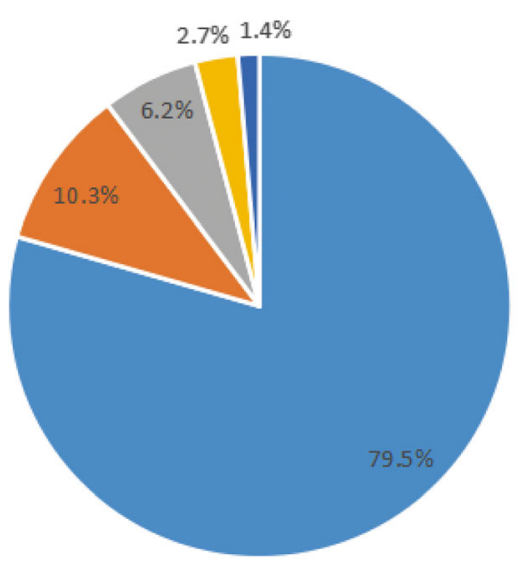

Autosomal trisomy

Monosomy X

Mosaicism or triploidy

Partial imbalance

Autosomal monosomy

Fig. 2 Abnormal results of HPLA 

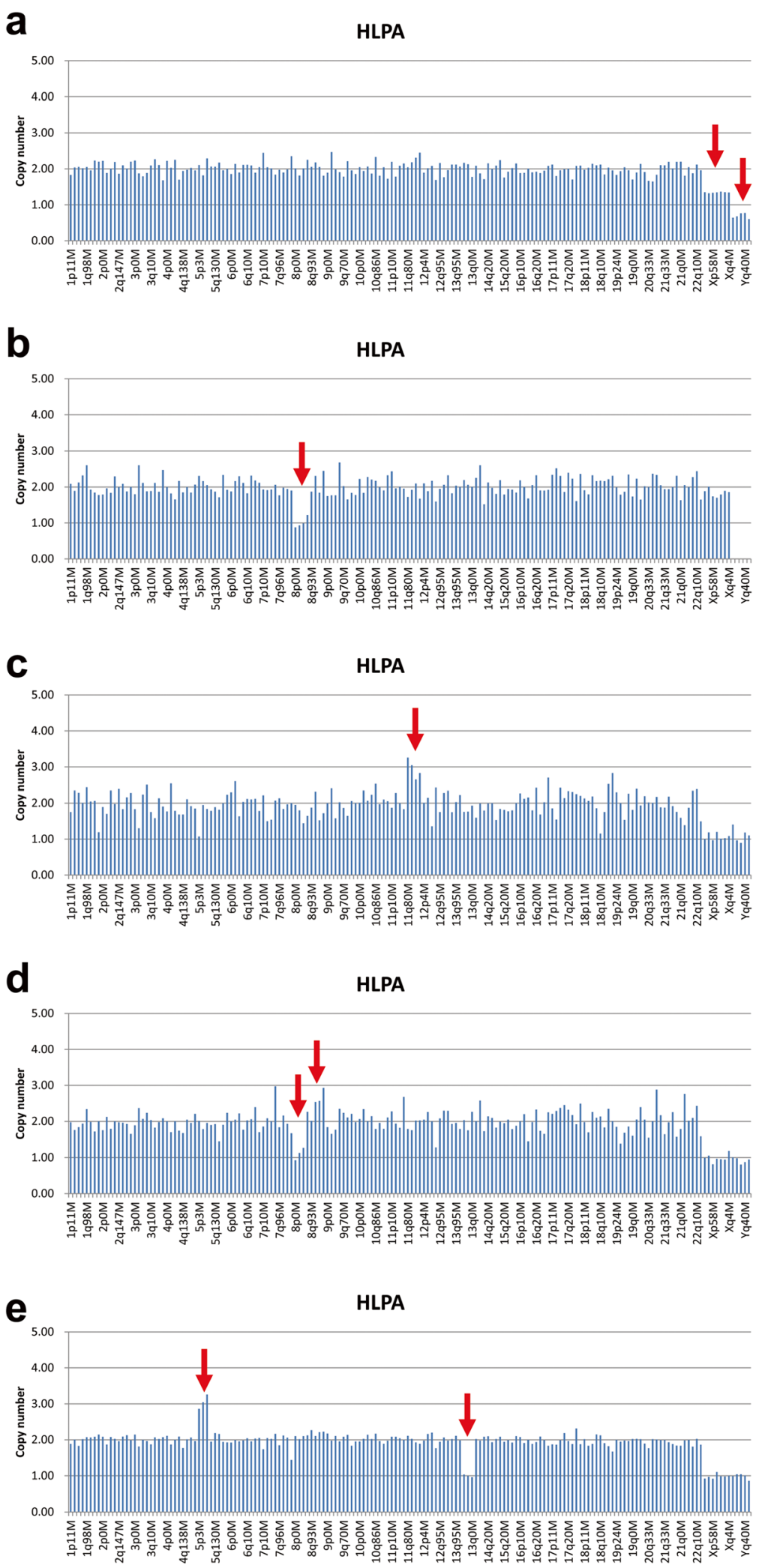

Fig. 3 Copy number variation measurements of five POC samples by HPLA. Chromosomal loci for probes were displayed in the $x$-axis, and $y$-axis showed the calculated copy number. CNVs were indicated by red arrows. (a) genetic mosaic 46,XX/46,XY or 69, XXY triploidy; (b) deletion of 8p; (c) duplication of 11q; (d) partial deletion of $8 p$ and partial duplication of 8q; (e) partial duplication of $5 p$ and partial deletion of 13q 
Analysis Suite (ChAS) 3.2 (Affymetrix, Santa Clara, CA, USA). CNVs were called at an minimum length of $50 \mathrm{~kb}$ containing at least 20 contiguous markers, and interpreted according to the standards and guidelines for interpretation and reporting of postnatal constitutional copy number variants released by the American College of Medical Genetics [11].

\section{Results}

No maternal cell contamination was detected in all 326 POC samples. The analysis strategy used in this study was summarized in Fig. 1. A total of 326 spontaneous abortion specimens were successfully tested using HPLA, and 146 samples of which yielded abnormal results $(146 / 326,44.8 \%)$. The remaining 180 samples with normal HPLA results were further analyzed by SNP-array, and abnormal results were observed in 32 cases $(32 / 326,9.8 \%)$.

\section{Abnormalities identified by HPLA}

The results of HPLA revealed that 146 of 326 samples $(44.8 \%)$ had chromosomal abnormalities. Among these, autosomal trisomy accounts for the largest proportion $(116 / 146,79.5 \%)$, followed by monosomy $\mathrm{X}$ (15/146, 10.3\%), mosaicism or triploidy $(9 / 146,6.2 \%)$, partial imbalance $(4 / 146,2.7 \%)$, and autosomal monosomy $(2 / 146,1.4 \%)$ (Fig. 2). As shown in Fig. 3a, the HPLA results of 9 cases indicated that the CNV values of probes on $\mathrm{X}$-chromosome were between 1.3-1.5, the CNV values of probes on Y-chromosome were between $0.6-0.8$, and the ratio of $\mathrm{CNV}$ values of probes on autosomes, $\mathrm{X}$-chromosome and Y-chromosome was about 3:2:1. Therefore, these 9 cases might be genetic mosaic $46, \mathrm{XX} / 46, \mathrm{XY}$ or 69 , XXY triploidy. 4 cases were found to have partial imbalance including deletion of $8 p$, duplication of $11 \mathrm{q}$, partial deletion of $8 \mathrm{p}$ and partial duplication of $8 \mathrm{q}$, and partial duplication of $5 p$ and partial deletion of 13q (Fig. 3b-e). 2 cases with autosomal monosomy were monosomy 21.

\section{Abnormalities detected by SNP-array}

One hundred eighty samples of spontaneous abortion tested to be normal by HPLA were further analyzed by SNP-array, and 32 samples (32/326, 9.8\%) yielded abnormal results, including $\mathrm{CNV}$, triploidy and loss of heterozygosity (LOH). Among these, CNV was the most common abnormality (23/32, $71.8 \%)$, which was divided into five subgroups: microduplication (7/32, $21.8 \%)$, mosaic microduplication (3/32, 9.4\%), microdeletion $(2 / 32,6.25 \%)$, mosaic microdeletion (2/32, $6.25 \%)$ and microduplication\&microdeletion (9/32, 28.1\%) (Fig. 4, Table 1). 7 cases were found to be 69, XXX triploidy, accounting for $21.8 \%$ of all the abnormalities. And 2 cases $(2 / 32,6.25 \%)$ were tested to have $\mathrm{LOH}$, including paternal uniparental disomy (UPD) of chromosome 7 and 27.532Mbp LOH at 5 p15.33p14.1 containing the key region of Cri du Chat Syndrome. In addition, 9 samples tested to be genetic mosaic $46, \mathrm{XX} / 46, \mathrm{XY}$ or 69 , XXY triploidy by HPLA were also analyzed by SNP-array, and the results indicated that all these samples were 69, XXY triploidy. And 4 cases reported to have partial imbalance by HPLA were confirmed by SNP-array.

\section{Discussion}

Elucidating the etiology of miscarriage is important for genetic consultation and management of the couple's future pregnancies. Although the causes of miscarriage could be complicated, genetic abnormalities, mainly aneuploidies, was the most frequent cause of first-trimester pregnancy loss, which are detected in $45-70 \%$ of sporadic miscarriages and $25-57 \%$ of recurrent miscarriages [12]. Thus exploring the genetic cause of pregnancy loss is of great importance.

HLPA is a method modified from MLPA to detect the copy number of 24 chromosomes by analyzing 170 genomic loci in one reaction $[9,10]$. In addition to aneuploidy, $\mathrm{SNP}$-array can also detect CNVs, $\mathrm{LOH}$, polyploidy and mosaicism at the genome-wide level. However, balanced chromosomal translocation and low-level mosaicism $(<10-$

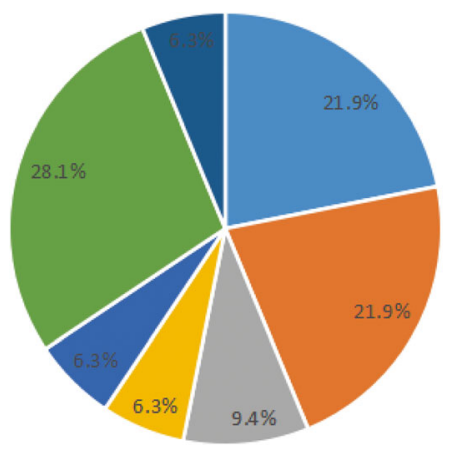

Triploidy

- Microduplication

- Mosaic microduplication

- Microdeletion

Mosaic microdeletion

Microduplication\&microdeletion

- $\mathrm{LOH}$

Fig. 4 Abnormal results of SNP-array 
Table 1 CNVs identified by SNP-array in spontaneous abortions

\begin{tabular}{|c|c|c|c|}
\hline No. & SNP-array result & Type & Interpretation \\
\hline 1 & 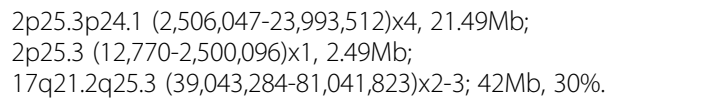 & Mosaic duplication, duplication\&deletion & Pathogenic \\
\hline 2 & $\begin{array}{l}\text { 10q26.1 1q26.3 (121,370,630-135,426,836)×3, 14.06Mb; } \\
\text { 12q24.33 }(131,262,269-133,257,821) \times 3,1.99 \mathrm{Mb}\end{array}$ & Duplication & Pathogenic \\
\hline 3 & Xq13.1q21.31 (71,514,629-88,581,567)x1-2, 17Mb, 22\%. & Mosaic deletion & VOUS \\
\hline 4 & 19p13.3p12(260,911-22,318,810)x1-2, 22Mb, 27\%. & Mosaic deletion & VOUS \\
\hline 5 & 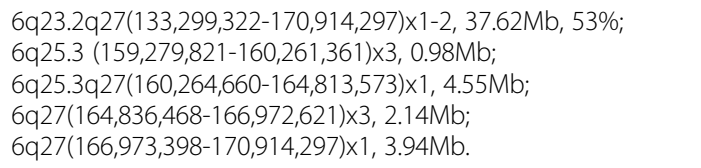 & Mosaic deletion, duplication\&deletion & Pathogenic \\
\hline 6 & $15 q 25.1 q 26.3(79,052,984-102,429,040) \times 2-3,23.38 \mathrm{Mb}, 32 \%$ & Mosaic duplication & VOUS \\
\hline 7 & $\begin{array}{l}\text { 7q33q36.3 (134,801,449-159,119,707)×1, 24.32Mb, 7q terminal } \\
\text { deletion syndrome; } \\
\text { 11q21q25(96,159,484-134,937,416)×3, 38.78Mb, 11q terminal } \\
\text { duplication syndrome. }\end{array}$ & Duplication\&deletion & Pathogenic \\
\hline 8 & $19 q 12(28,870,035-29,879,116) \times 4,1.00 \mathrm{Mb}$ & Duplication & Likely benign, maternal origin \\
\hline 9 & $\begin{array}{l}\text { 7q36.3 }(155,329,202-157,529,779) \times 4,2.20 \mathrm{Mb} \\
\text { 7q36.3 }(157,536,855-158,879,019) \times 1,1.34 \mathrm{Mb} \\
\text { 19p13.3p12(260,911-58,956,816)x1-2, chr19, 34\%. }\end{array}$ & Mosaic deletion, duplication\&deletion & Pathogenic, de novo \\
\hline 10 & Xp22.31 $(7,143,928-7,690,002) \times 1,0.55 \mathrm{Mb}$ & Deletion & Likely benign \\
\hline 11 & 18p11.21 (13,800,292-14,348,385)×3, 0.55Mb & Duplication & Likely benign \\
\hline 12 & 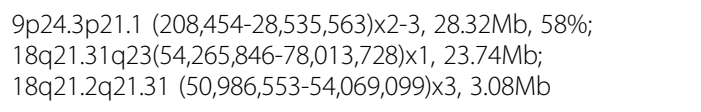 & Mosaic duplication, duplication\&deletion & Pathogenic \\
\hline 13 & $\begin{array}{l}\text { 4q31.23q35.2 (149,107,084-190,957,460)×3, 41.85Mb; } \\
\text { 7q34q36.3 }(143,084,599-159,119,707) \times 1,16.04 \mathrm{Mb}\end{array}$ & Duplication\&deletion & Pathogenic \\
\hline 14 & Xp22.31 (6,455,150-8,135,568)×2, 1.68Mb. & Duplication & Likely benign, maternal origin \\
\hline 15 & $1 \mathrm{p} 22.2(89,523,245-91,159,433) \times 1,1.64 \mathrm{Mb}$ & Deletion & VOUS \\
\hline 16 & 7q22.1q36.3 $(101,562,358-159,119,707) \times 2-3,57.56 \mathrm{Mb}, 37 \%$ & Mosaic duplication & VOUS \\
\hline 17 & $\begin{array}{l}\text { 5p15.33p13.3 }(113,576-29,104,386) \times 3,28.99 \mathrm{Mb} \\
13 q 22.3 q 34(77,782,493-115,011,636) \times 1,37.23 \mathrm{Mb} .\end{array}$ & Duplication\&deletion & Pathogenic \\
\hline 18 & $2 q 37.3(238,138,565-238,616,893) \times 3,0.48 \mathrm{Mb}$ & Duplication & Likely benign \\
\hline 19 & 12q24.23 $(119,276,763-119,682,258) \times 3,0.41 \mathrm{Mb}$ & Duplication & VOUS \\
\hline 20 & 20p12.3p12.2 (8,633,732-9,375,262)×3, 0.74Mb. & Duplication & VOUS \\
\hline 21 & $\begin{array}{l}\text { 2q37.1q37.3 (235,368,568-237,312,027)×4, 1.94Mb; } \\
\text { 2q37.3 }(238,781,791-242,782,258) \times 1,4 M b\end{array}$ & Duplication\&deletion & Pathogenic \\
\hline 22 & $\begin{array}{l}\text { 18q22.2q23(68,019,984-78,013,728)x1, 9.99Mb; } \\
3 q 27.3 q 29(186,570,452-195,835,968) \times 3,9.27 \mathrm{Mb} .\end{array}$ & Duplication\&deletion & Pathogenic \\
\hline 23 & 20p13q13.33 (61,661-62,913,645)×2-3, 62.85Mb, 31\%. & Mosaic duplication & Pathogenic \\
\hline
\end{tabular}

$15 \%)$ could not be identified by SNP-array. The turnaround time of HPLA is within 24h, which is shorter than that of SNP-array (2-3d) and conventional karyotyping (21-30d). The cost of HPLA is comparable to that of conventional karyotyping and much lower than that of SNP-array (1/10 of the cost of SNP-array). And in our institution, the failure rates of genetic analysis of POC by HPLA, SNP-array and conventional karyotyping are $2.1 \%, 1 \%$ and $35.6 \%$ respectively (unpublished data). Here we report an efficient and cost-effective HLPA/SNP-array strategy for genetic analysis of POC. Our analysis results of 326 POC specimens using this strategy indicated that the overall abnormality rate was 54.6\%. Among these, $44.8 \%$ of samples were found to be abnormal by HLPA and SNP-array detected $9.8 \%$ additional chromosomal abnormalities, which is consistent with a previous report that CMA identified 13\% (95\% CI 8.0-21.0) additional chromosome aberrations over conventional karyotyping [13]. And the expense of SNP-array analysis is avoided for $40.8 \%$ of samples found to be aneuploid by HPLA. Hence the combination of HLPA and SNP-array in 
genetic analysis of POC is more cost-effective than testing by SNP-array alone.

Previous studies revealed that submicroscopic CNVs could be one of genetic causes in pregnancy losses [1419].In this study, $23 \mathrm{CNVs}$ were identified in 326 POC samples using SNP-array, of which $11 \mathrm{CNVs}$ were interpreted as pathogenic for these CNVs were cytogenetically visible alterations $(>3-5 \mathrm{Mb})$ without wellestablished cytogenetic heteromorphisms, and 7 CNVs were classified as VOUS because whether these CNVs cause spontaneous abortions is still an open question (Table 1). Moreover, $\mathrm{LOH}$ and triploidy were detected in 9 cases by SNP-array, which were tested to be normal by HPLA. In addition, 4 POC samples found to have partial imbalance by HPLA were confirmed by SNParray, indicating that HPLA can also detect microduplications and microdeletions $[9,10]$.

\section{Conclusions}

A combined HLPA and SNP-array analysis is an efficient and cost-effective strategy for genetic analysis of POC. We recommend the use of HLPA for initial genetic screening on POC, and subsequent SNP-array analysis on POC with normal HLPA results.

\section{Abbreviations}

aCGH: Array-based comparative genomic hybridization; BOBs: BACs-on-Beads; CMA: Chromosomal microarray analysis; CNVs: Copy number variations; FISH: Fluorescence in situ hybridization; HLPA: High-throughput ligationdependent probe amplification; LOH: Loss of heterozygosity; MLPA: Multiple ligation-dependent probe amplification; NGS: Next generation sequencing; POC: Products of conception; QF-PCR: Quantitative fluorescent PCR; SNParray: Single nucleotide polymorphism array; STR: Short tandem repeat; UPD: Uniparental disomy

\section{Acknowledgements}

We would like to thank the patients for participating in this research project. The authors also acknowledge all members of the laboratory.

\section{Authors' contributions}

JX and $H L$ are responsible for testing strategy design and manuscript preparation. JM and XS carried out the HLPA and SNP-array analysis. Data analysis and genetic counselling were conducted by HW, HL and TW. All authors read and approved the final manuscript.

\section{Funding}

This work is supported by Jiangsu Province Association of Maternal and Child Health Project (FYX201603), Jiangsu Provincial commission of health and family planning (H2017073), Jiangsu Maternal and Children health care key discipline (FXK201748), Jiangsu Maternal and Children health care research project (F201603), Jiangsu Provincial Medical Innovation Team (CXTDB2017013), Suzhou Key Medical Center (SZZX201505), Suzhou Introduced Project of Clinical Medical Expert Team (SZYJTD201708), Suzhou Industry Technology Innovation Project (SYS201770 and SS201873) and Ningbo Health Branding Subject Fund (PPXK2018-06).

\section{Availability of data and materials}

All data are available upon request.

\section{Ethics approval and consent to participate}

The study was approved by the institutional ethics committee of the Affiliated Suzhou Hospital of Nanjing Medical University. Written informed consent were obtained.
Consent for publication

Not applicable.

\section{Competing interests}

The authors declare that they have no competing interests.

\section{Author details}

${ }^{1}$ Center for Reproduction and Genetics, The Affiliated Suzhou Hospital of Nanjing Medical University, Suzhou, Jiangsu, China. ${ }^{2}$ Center for Reproduction and Genetics, Suzhou Municipal Hospital, Suzhou, Jiangsu, China.

${ }^{3}$ Department of Gynaecology, The Affiliated Suzhou Hospital of Nanjing Medical University, Suzhou, Jiangsu, China. ${ }^{4}$ Ningbo Municipal Key Laboratory of Comprehensive Prevention and Treatment of Birth Defects, Ningbo Women \& Children's Hospital, Ningbo, Zhejiang, China.

Received: 27 April 2019 Accepted: 23 August 2019

Published online: 02 September 2019

\section{References}

1. Rai R, Regan L. Recurrent miscarriage. Lancet. 2006;368(9535):601-11. https://doi.org/10.1016/S0140-6736(06)69204-0.

2. Larsen EC, Christiansen OB, Kolte AM, Macklon N. New insights into mechanisms behind miscarriage. BMC Med. 2013;11:154. https://doi.org/1 0.1186/1741-7015-11-154.

3. Menasha J, Levy B, Hirschhorn K, Kardon NB. Incidence and spectrum of chromosome abnormalities in spontaneous abortions: new insights from a 12-year study. Genet Med. 2005;7(4):251-63. https://doi.org/10.1097/01.GIM. 0000160075.96707 .04

4. Nagaishi M, Yamamoto T, linuma K, Shimomura K, Berend SA, Knops J. Chromosome abnormalities identified in 347 spontaneous abortions collected in Japan. J Obstet Gynaecol Res. 2004;30(3):237-41. https://doi. org/10.1111/j.1447-0756.2004.00191.x.

5. Vermeesch JR, Fiegler $H$, de Leeuw N, Szuhai K, Schoumans J, Ciccone $\mathrm{R}$, et al. Guidelines for molecular karyotyping in constitutional genetic diagnosis. Eur J Hum Genet. 2007;15(11):1105-14. https://doi.org/10.103 8/sj.ejhg.5201896.

6. Gao J, Liu C, Yao F, Hao N, Zhou J, Zhou Q, et al. Array-based comparative genomic hybridization is more informative than conventional karyotyping and fluorescence in situ hybridization in the analysis of first-trimester spontaneous abortion. Mol Cytogenet. 2012;5(1):33. https://doi.org/10.11 86/1755-8166-5-33.

7. Dong Z, Zhang J, Hu P, Chen H, Xu J, Tian Q, et al. Low-pass wholegenome sequencing in clinical cytogenetics: a validated approach. Genet Med. 2016:18(9):940-8. https://doi.org/10.1038/gim.2015.199.

8. Sahoo T, Dzidic N, Strecker MN, Commander S, Travis MK, Doherty C, et al. Comprehensive genetic analysis of pregnancy loss by chromosomal microarrays: outcomes, benefits, and challenges. Genet Med. 2017;19(1):839. https://doi.org/10.1038/gim.2016.69.

9. Chen S, Liu D, Zhang J, Li S, Zhang L, Fan J, et al. A copy number variation genotyping method for aneuploidy detection in spontaneous abortion specimens. Prenat Diagn. 2017;37(2):176-83. https://doi.org/10.1002/pd.4986.

10. Yang L, Tang Y, Lu M, Yang Y, Xiao J, Wang Q, et al. Novel rapid molecular diagnosis of fetal chromosomal abnormalities associated with recurrent pregnancy loss. Acta Obstet Gynecol Scand. 2016;95(12):1433-40. https:// doi.org/10.1111/aogs.13026.

11. Kearney HM, Thorland EC, Brown KK, Quintero-Rivera F, South ST. Working Group of the American College of Medical Genetics Laboratory Quality Assurance C. American College of Medical Genetics standards and guidelines for interpretation and reporting of postnatal constitutional copy number variants. Genet Med. 2011;13(7):680-5. https://doi.org/10.1097/GIM. Ob013e3182217a3a.

12. Massalska D, Zimowski JG, Bijok J, Pawelec M, Czubak-Barlik M, Jakiel G, et al First trimester pregnancy loss: Clinical implications of genetic testing. J Obstet Gynaecol Res. 2017;43(1):23-9. https://doi.org/10.1111/jog.13179.

13. Dhillon RK, Hillman SC, Morris RK, McMullan D, Williams D, Coomarasamy A, et al. Additional information from chromosomal microarray analysis (CMA) over conventional karyotyping when diagnosing chromosomal abnormalities in miscarriage: a systematic review and meta-analysis. BJOG. 2014;121(1):11-21. https://doi.org/10.1111/1471-0528.12382.

14. Chen Y, Bartanus J, Liang D, Zhu H, Breman AM, Smith لL et al. Characterization of chromosomal abnormalities in pregnancy losses reveals 
critical genes and loci for human early development. Hum Mutat. 2017; 38(6):669-77. https://doi.org/10.1002/humu.23207.

15. Rajcan-Separovic E, Diego-Alvarez D, Robinson WP, Tyson C, Qiao Y, Harvard $C$, et al. Identification of copy number variants in miscarriages from couples with idiopathic recurrent pregnancy loss. Hum Reprod. 2010;25(11):2913-22. https://doi.org/10.1093/humrep/deq202.

16. Levy B, Sigurjonsson S, Pettersen B, Maisenbacher MK, Hall MP, Demko Z, et al. Genomic imbalance in products of conception: single-nucleotide polymorphism chromosomal microarray analysis. Obstet Gynecol. 2014; 124(2 Pt 1):202-9. https://doi.org/10.1097/AOG.0000000000000325.

17. Rosenfeld JA, Tucker ME, Escobar LF, Neill NJ, Torchia BS, McDaniel LD, et al, Diagnostic utility of microarray testing in pregnancy loss. Ultrasound Obstet Gynecol. 2015;46(4):478-86. https://doi.org/10.1002/uog.14866.

18. Zhou Q, Wu SY, Amato K, DiAdamo A, Li P. Spectrum of Cytogenomic Abnormalities Revealed by Array Comparative Genomic Hybridization on Products of Conception Culture Failure and Normal Karyotype Samples. $J$ Genet Genomics. 2016;43(3):121-31. https://doi.org/10.1016/j.jgg.2016.02.002

19. Li H, Liu M, Xie M, Zhang Q, Xiang J, Duan C, et al. Submicroscopic chromosomal imbalances contribute to early abortion. Mol Cytogenet. 2018; 11:41. https://doi.org/10.1186/s13039-018-0386-0.

\section{Publisher's Note}

Springer Nature remains neutral with regard to jurisdictional claims in published maps and institutional affiliations.

Ready to submit your research? Choose BMC and benefit from:

- fast, convenient online submission

- thorough peer review by experienced researchers in your field

- rapid publication on acceptance

- support for research data, including large and complex data types

- gold Open Access which fosters wider collaboration and increased citations

- maximum visibility for your research: over $100 \mathrm{M}$ website views per year

At BMC, research is always in progress.

Learn more biomedcentral.com/submissions 